\title{
MARAVILHOSO INFORMACIONAL: CRÍTICA DA FILOSOFIA DA INFORMAÇÃO SOB UMA REFLEXÃO HERMENÊUTICA ENTRE MEDIEVO E MODERNIDADE ${ }^{1}$
}

\author{
Gustavo Silva Saldanha \\ Instituto Brasileiro de Informação em Ciência e Tecnologia \\ (IBICT)/Universidade Federal do Rio de Janeiro (UFRJ) \\ Universidade Federal do Estado do Rio de Janeiro - UNIRIO \\ gustavosaldanha@ibict.br \\ saldanhaquim@gmail.com
}

\begin{abstract}
Resumo
O objetivo deste estudo é discutir as questões inerentes aos conceitos de informação e conhecimento a partir de uma epistemologia histórica. A análise a partir de um olhar comparado entre os séculos XIII e XX contribui para o esclarecimento crítico da elaboração de tais conceitos e seu uso. Ambos os períodos refletem momentos de profundas transformações sociais orientadas no estatuto epistemológico das instituições de ensino e de pesquisa. Propomos como metodologia um estudo hermenêutico das noções de informação e conhecimento, junto de complexidade e maravilhoso, nos períodos mencionados. Nosso campo empírico posiciona-se em torno de dois indícios da formação discursiva: uma filosofia do conhecimento na Idade Média, explicitada nas práticas das primeiras universidades que florescem no século XII, e uma filosofia da informação, que se desenvolve na atualidade na epistemologia da Ciência da Informação. O estudo permite um olhar crítico sobre certas classificações consagradas, como a Idade Média como período sombrio ao conhecer e apenas fundamentado na noção de acesso ao conhecimento pela narrativa, e a pós-modernidade como etapa histórica promotora do conhecer, dependente tão somente da informação objetiva para a apreensão dos saberes.
\end{abstract}

Palavras-chave: Filosofia da Informação. Conhecimento. Informação. Idade Média. Modernidade.

\section{INFORMATIONAL WONDERFUL: \\ CRITICISM OF INFORMATION PHILOSOPHY FROM A HERMENEUTICAL REFLECTION BETWEEN MIDDLE AGES AND MODERNITY}

\begin{abstract}
The aim of this study is to discuss the issues relating to the concepts of information and knowledge from a historical epistemology. The analysis from a comparative epistemology between the thirteenth and twentieth centuries contributes to the clarification of these conditions. Both periods reflect moments of profound social transformation aimed at educational institutions. We propose as a research method a hermeneutical study of the notions of complexity and knowledge between the periods mentioned. Our empirical field is positioned around two indications training: a philosophy of knowledge in the Middle Ages spelled practices of the first universities that bloom in the twelfth century, and a philosophy of information, which develops at present in the epistemology of Information Science. The study allows touch clues that contribute to understanding the causes of resumption of complex thinking nowadays. Similarly, the analysis illuminates the cuttings on which are supported the concept that knowledge and as used in this society.
\end{abstract}

Keywords: Philosophy of Information. Knowledge. Information. Middle Age. Modernity.

\footnotetext{
${ }^{1} \mathrm{O}$ estudo é parte integrante do projeto "Trilhar o Trivium: a filosofia da Ciência da Informação na tradição filosófica da linguagem". E fruto direto de estudos desenvolvidos nos últimos cinco anos, tendo a primeira versão reduzida apresentada no IV Encontro Ibérico EDIBCIC, 2009, em Coimbra, sob o título "A complexidade e o conhecimento nos séculos XIII e XX: uma reflexão epistemológica", publicado em "A Ciência da Informação criadora de conhecimento. Coimbra: Impressa da Universidade de Coimbra, 2009. v. 2. p. 85-99."
} 


\title{
1 Introdução
}

\begin{abstract}
Como porém a tragédia não só é imitação de uma ação completa, como também a de casos que suscitam o terror e a piedade, e estas emoções se manifestam principalmente quando se nos deparam ações paradoxais, e, perante casos semelhantes, maior é o espanto que ante os feitos do acaso e da fortuna (porque ainda entre os eventos fortuitos, mais maravilhosos parecem os que se nos afiguram acontecidos de propósito [...]), daqui se segue serem indubitavelmente os melhores, os mitos assim concebidos.
\end{abstract}

Aristóteles, Arte Poética

A complexidade como categoria de análise ganha evidência nos gestos discursivos contemporâneos. O século XX retoma investigações em torno da multiplicidade dos itinerários existentes para realização da viagem ao conhecimento e da presença de ângulos alternativos de contemplação do livro do mundo. Cabe-nos perguntar o que significa o “complexo" e o "conhecimento" no cotidiano contemporâneo.

Se em um período remoto, medieval, o acesso ao conhecimento pela via da complexidade teria ocorrido a partir das narrativas, por outro lado, nos tempos recentes, o conhecer ligado ao complexo se faria pela via da informação. Se, na Idade Média, as práticas do ensino e da aprendizagem conviviam com o imaginário povoado pela presença do maravilhoso no cotidiano, como na conceituação de Jacques Le Goff, noção imersa na intersubjetividade dos discursos narrativos, na esfera temporal do século passado a informação substituiria, após um possível esgotamento da modernidade, o sublime no cotidiano como possibilidade de acesso ao saber, no intuito de afastar o contato com o maravilhoso, este tomado como ruído prejudicial à viagem ao livro do mundo segundo uma visão de mundo positivista, como demonstrado em Borko e Brookes no âmbito da Ciência da Informação - CI.

No entanto, a informação terminaria por se tornar o maravilhoso na chamada pósmodernidade, na medida em que tenderia a aproximar, através das tecnologias da comunicação, diferentes sociedades em torno de um imaginário que consagra - ou "fetichiza" - a mensagem midiática como essência da aprendizagem e único caminho para a aquisição de saberes. A análise comparada entre os séculos XIII e XX contribui para o esclarecimento destas condições. Ambos os períodos refletem momentos de profundas transformações sociais orientadas por movimentações sensíveis no estatuto epistemológico da organização dos saberes.

\section{Hermenêutica das investigações acerca das "explosões informacionais": informações registradas, documentos, livros...}


Quer nas tragédias como peripécia, quer nas episódicas, podem os poetas obter o desejado efeito mediante o maravilhoso.

O século XIII revela um contato com a Antiguidade clássica a partir do acesso a personagens não necessariamente ligados à cultura cristã. São marcas da virada do século XII para o XIII o rápido crescimento demográfico, com a constituição de burgos e a circulação de ideias profanas, ou saberes registrados que iam além do crivo cristão, ainda que sob a sombra deste estivessem. As universidades de Paris, Oxford e Bolonha são manifestações destas transformações e da grande abertura às discussões. A "descoberta" de Aristóteles, traduzido por árabes e outros personagens históricos do medievo, terá, nesta medida, papel preponderante na provocação de diferentes formas de pensar (SARANYANA, 2006, p. 258). Surge, neste contexto, uma teoria do conhecimento que consagra a razão como elemento primordial dos saberes, que toma a realidade sensível - a natureza - como objeto passível de apreensão por um sujeito, chamado cognoscente (GHISALBERTI, 2001).

Serão ainda esferas identitárias deste processo a grande produção de livros até então não vivenciada, visando fundamentalmente à aquisição, a guarda, a interpretação, o controle e a transmissão dos saberes. A emergência do "conhecimento" e da "complexidade" do mundo diante da circulação de ideias conduz até um imaginário de produção de registros de conhecimento que levará, como lembrado por Ortega y Gasset (2006), até o desenvolvimento da imprensa. Desta maneira, uma dada "explosão informacional" claramente demarcada no mundo material e virtual do duzentos podia ser identificada.

Em artigo, o historiador Peter Burke (2002) também discute os problemas causados por uma certa "explosão informacional". Seu ângulo temporal de análise, no entanto, é o século XV e o elemento histórico sobre o qual fundamenta sua interpretação está pautado na invenção da imprensa e no personagem Gutenberg. O breve trabalho de Burke (2002) chama a atenção para alguns pontos que, em geral, são negligenciados na leitura das transformações sociais no âmbito da organização dos saberes. No caso do conceito de "explosão informacional" temos, de modo comum, no âmbito da epistemologia da CI, a definição da grande produção de documentos na virada dos séculos XIX para o XX como fator determinante para a transformação na forma do conhecer e um dos indícios empíricos da ampliação da complexidade do conhecimento - ou, ainda, a multiplicação descontrolada de registros eletrônicos que se seguirá após a $2^{\mathrm{a}}$ Guerra Munidal. Outros termos são utilizados nos estudos informacionais para definir este momento - Wersig (1993, p. 230) falará em um dilúvio literário - literature flood - e Pinheiro (2002, p. 72), tratará estas transformações 
como "explosão bibliográfica" e "caos documentário". No entanto, também a forma de Peter Burke observar a realidade apresentada define a estrutura do objeto observado. $\mathrm{O}$ trabalho de Burke (2002), desta maneira, nos propõe um olhar crítico sobre o que o próprio historiador chamaria de "descrições triunfalistas" sobre a invenção de Gutenberg, procurando enxergar nela tanto seus desdobramentos solucionadores como aqueles que determinaram um conjunto de narrativas "catastrofistas".

A mesma discussão trazemos para os séculos XIX e XX e a historiografia da CI. A denominada "explosão informacional" não apenas se configura como fenômeno comum no discurso de cientistas e profissionais da informação, mas se apresenta como acontecimento definitivo que teria, junto de outras múltiplas evidências factuais, apresentado os elementos que determinariam a emergência do próprio campo da informação em meados do século anterior como disciplina científica (BOYCE, KRAFT, 1985; SHERA, CLEVELAND, 1977). Para além disso, tais discursos apontam que este fenômeno revolucionaria o nosso modo de conhecer e transformaria a "complexidade" em uma categoria inerente e fundamental para qualquer ponto de vista epistemológico, percebida a aproximação temporal entre o nascimento do campo e a abertura de discussões em torno da interdisciplinaridade, como aquelas influenciadas pela leitura de pensadores contemporâneos como Boaventura Santos, Edgar Morin e Hilton Japiassu. Mais especificamente, este fenômeno seria um dos causadores diretos para a constituição de um domínio filosófico, tratado como "filosofia da informação".

Sabemos que, antes de mais nada, a "explosão informacional" é um fenômeno e, como tal, uma operação subjetiva de elaborar o próprio fenômeno e, ainda, de ver, vivenciar e interpretar tal acontecimento, ou seja, em outras palavras, um processo discursivo. Saber interpretá-lo é saber reconhecê-lo, como também desconstruí-lo em seus triunfos e catástrofes. Saber interpretá-lo é, necessariamente, tê-lo experienciado. Um estudo comparativo com outros regimes epistêmicos permite-nos perceber como, em diferentes momentos, é possível situar relevantes "explosões informacionais", como é o caso do século XIII.

Mas o que é uma "explosão informacional"? Em linhas gerais, tratando como o termo se apresenta na epistemologia da CI, podemos considerar a pandemia, em um determinado momento histórico, de registros do conhecimento em relação à proporção potencial de intérpretes que são, direta ou indiretamente, por ele afetados. Chamamos a atenção para o fato de que não tratamos o usuário como receptor, mas intérprete. Isto já altera, ainda que de maneira parcial, a forma de abordar uma "explosão informacional" como em geral é identificada na epistemologia do campo em suas primeiras manifestações, em parte ainda imbricada com a Teoria Matemática da Comunicação de Claude Shannon e Warren Weaver. 
O exemplo mais consagrado que possuímos refere-se à epistemologia alexandrina. No contexto da principal capital do Helenismo, encontramos uma produção bibliológica e a determinação da mimese como fundamento ontológico dos saberes documentais. Temos neste contexto a sedimentação da ars grammatica, dividida em duas: a arte menor, que contempla a leitura segundo a prosódia, a explicação das figuras retóricas, o esclarecimento de significantes e significados, a etimologia e as regras da gramática (analogia), e a arte maior, que se voltava para o juízo sobre os poemas ou crítica literária, resolvendo questões de estética e de autenticidade (SOUSA, 1966). Verifica-se aqui, claramente, o primeiro "dilúvio literário" enfrentado por uma sociedade, equiparável à prensa e à web, se nos permitimos considerar a expressão demográfica e o contexto sócio-técnico do período em questão. Ao mesmo tempo, aparecem, neste momento, métodos, técnicas e reflexões que sugerem a formulação de uma epistemologia da organização dos saberes que influenciará toda a Idade Média, o Renascimento e a Idade Moderna.

A ressalva crítica se dá, pois, como é apresentado na epistemologia do campo, a CI teria nascido - se vislumbrado seu nascimento no período da Segunda Guerra Mundial como ciência diretamente voltada para a sociedade científica, ou seja, para uma informação reduzida à sua condição de informação científica e tecnológica, "coisificada" à moda positivista. Logo, a "informação" da expressão "explosão informacional” diz respeito apenas a uma comunidade, bastante restrita e fechada no contexto social-mundial, a comunidade pesquisadores. Do mesmo modo, esta "informação" designa um dado objetivo quantificável. A verificação nos faz constatar a parcialidade do fator intérprete na definição de uma “explosão informacional”, parcialidade alertada pelas revisões cognitivista e, principalmente, pragmatista e pós-estruturalista de nosso campo.

\section{A desmistificação das "explosões informacionais" e o estatuto do "conhecimento" e da “complexidade" nos regimes epistemológicos da organização do saberes}

\footnotetext{
O maravilhoso tem lugar primacial na tragédia; mas na epopeia, porque ante nossos olhos não agem atores, chegar a ser admissível o irracional, de que muito especialmente deriva o maravilhoso.
}

Aristóteles, Arte Poética

De um modo geral, tendo como ponto de partida a emergência dos estudos e práticas da organização do saberes, podemos reconhecer que o campo sobrevive sob a instauração de crises intermitentes na produção e distribuição de manifestações cumulativas de uma cultura material. Assim como os desdobramentos da circulação de ideias no século XIII provocam a 
urgência de uma "industrialização" no processo de registro dos saberes, "levando" à invenção da prensa, o fato histórico desdobrado deságua, por sua vez, na evidência de novas ideias, conduzindo à institucionalização da Biblioteconomia no século XIX. Do mesmo modo, a hiperespecialização dos ramos do conhecimento, leva à necessidade de novos serviços e produtos no campo da informação científica e especializada, provocando a transformação nos meios - o que "daria origem" à transmissão de sinais -, que por sua vez provocaria a definição, da institucionalização do discurso de uma ciência para informação. Desta forma, a complexidade envolve no campo a espiral dinâmica de a) circulação dos saberes, b) construção de canais para fixação, armazenamento e transmissão e c) formação/formalização de uma cultura discursiva de assimilação de tais saberes, tendo os regimes epistemológicos do campo fortes oscilações quando diante do aprofundamento ou de distanciamento de uma destas três instâncias.

Tomando como ponto de referência não apenas os objetos - os documentos -, mas também os potenciais intérpretes, permitimo-nos um olhar crítico sobre a definição da "explosão" pelo fato singular, porém unilateral, da produção de massa. Os discursos que apontaram como fenômeno determinada multiplicação de registros do conhecimento, os olhares verdadeiramente potenciais que se interessam para estes objetos, os modos de divulgação, controle e recepção, todas estas instâncias nos levam a rever minuciosamente as contingências de uma "explosão informacional". Em outras palavras, em um ponto de vista hermenêutico, tais ponderações nos fariam perguntar: "explosão informacional" como e para quem?

Neste sentido, a "explosão informacional” propagada pela discursividade da CI é, em geral, a apresentação de um fenômeno pandêmico de natureza urbana que se direcionava, fundamentalmente, a uma sociedade letrada ainda pequena, mesmo no século XX, cuja possibilidade virtual de recepção dos registros de conhecimento multiplicados era, em tese, restrita. Mesmo se tomada a partir da Segunda Guerra Mundial, quando começamos a tratar de uma "outra" "explosão informacional", pensar o fenômeno como elemento que seria o motor para o nascimento de um outro campo, devido a uma alteração na estrutura do conhecimento, e enxergar neste a semente da "complexidade", é rever criticamente os usos da expressão e seus desdobramentos, assim como nos propõe Peter Burke (2002).

Em seu discurso historiográfico e epistemológico, podemos indicar que a CI é fruto de uma passagem das ciências documentais à ciência da informação, como podemos trabalhar a partir do título da obra de Silva \& Ribeiro (2002). No entanto, a possível "retomada" do documento a partir dos anos 1990 até os dias atuais como objeto da CI, como em Frohmann 
(1999), nos faz perceber que, ao contrário de uma passagem, o campo é apenas “um”, ou seja, seu "modo de conhecer" se baseia na espiral que gira em torno da organização dos saberes - e a passagem do documento à informação não percebe uma linha evolutiva, mas circular e ininterrupta: antes da apropriação do conceito de "documento" havia o conceito de "informação" que está depois do "documento" que, por sua vez, está antes, durante e após a própria manipulação conceitual contemporânea da noção de "informação". Em outras palavras, a CI nunca "abandonou" o documento, e, naturalmente, o livro, ao postular uma epistême para a informação; do mesmo modo, a organização dos saberes sempre trabalhou com um modelo de informação - a meta-informação -, muito antes de consagrarmos o significante "informação" como pedra de toque para os discursos da CI. A crítica de Day (2005) é, a nosso ver, uma síntese esclarecedora da questão e uma provocação às certezas epistemológicas no campo da informação, ao chamar a atenção para os usos da noção de informação, como uma expressão metafísica de nossa busca no campo, quando na verdade os significados de informação, na prática, remetiam ao significante documento.

Isto se dá porque, ao tratar da informação, a CI abordou fundamentalmente a "informação registrada" - ou as possibilidades de sua fixação. A partir desta, ela trabalha com todas as nuances, principalmente com o esclarecimento de Harold Borko, em 1968, que podem levar os saberes até seu registro, aproximando-se assim de uma possível informação não registrada, mas desde que também transmissível, ou seja, capaz de ser transmitida por algum canal que a "materialize" - donde se originarão os enfoques cognitivos, pragmatistas e pós-estruturalistas do campo.

A ideia histórica do livro - este, por mais de um milênio livre de sua expressão paradigmática conferida por Gutenberg, que lhe cobriu com as características as quais atualmente confundimos a raiz biblión - esteve ligada a tudo aquilo que guarda e transmite conhecimento. Recuperada por Paul Otlet, porém sob outro termo, documento, esta noção será, segundo diferentes autores, como observam os pesquisadores portugueses Silva \& Ribeiro (2002), um dos pontos fundamentais para a identificação da emergência do positivismo no campo, o que levaria à construção - então neopositivista - do neologismo “ciência da informação". A partir de então, os estudiosos do campo passariam a adotar outro significante, a informação, integrando os estudos voltados para organização dos saberes a diferentes fronteiras que tomavam o termo informação como objeto.

Por sua vez, o fenômeno do qual esta "informação" que está na expressão "ciência da informação" se originaria - ou seja, a "explosão informacional", esta, tratada indiscriminadamente, como um evento singular em si, como na crítica de Day (2005) - seria o 
responsável direto pela nova configuração em torno do "conhecer" e do "complexo", provocando uma ruptura no regime epistemológico do campo. A pandemia de registros do conhecimento - informações registradas, ou documentos, ou apenas livros - nos últimos três séculos conduziria, para uma epistemologia da organização dos saberes, à amplificação e à hibridização dos domínios do conhecimento.

Cabe-nos analisar criticamente estes postulados. Discutindo a seguir, de forma concisa e panorâmica, a ideia de uma filosofia do conhecimento no século XIII e uma filosofia da informação no século XX. Procuramos desconstruir as abordagens que, em geral, abordagem a complexidade como categoria contemporânea, e o conhecimento como oriundo da informação, de modo a perceber o fenômeno não apenas pelo seu caráter "científico", “objetivo", mas também por suas contradições e silêncios advindos de uma determinação cultural, que fundamenta o "maravilhoso" também como esfera do conhecer por trás e pela frente do que se apresenta como "complexo".

\subsection{Uma certa "explosão informacional" no século XIII: em torno de uma "filosofia do conhecimento" para a organização dos saberes...}

A partir da primeira cruzada, de 1095, comandada por Urbano II, identificamos a consolidação de diferentes rotas econômicas. Neste processo, inicia-se um período de rápida urbanização, ganhando destaque cidades do mediterrâneo e dos países baixos. Surge assim um conjunto de escolas urbanas. Inclui-se nesta movimentação histórica a renovação da administração destes burgos, que passa para a mão de leigos. (SARANYANAVA, 2006)

O século XII será tratado, após as transformações do século anterior, como século do Renascimento, antecipando assim as inferências em geral elevadas aos séculos XV e XVI, no contexto artístico italiano. Instituição mais característica da Idade Média, a universidade chegará até os dias atuais praticamente sem mudanças substanciais. Como afirmará Boni (2000), esta condição justificaria a afirmação de que nossas formas de saber contemporâneas têm sua origem nestas instituições de quase mil anos. Temos aqui, no olhar de Verger (2001), a rápida passagem das escolas monásticas para as escolas catedrais e destas para o que hoje conceituamos "universidades".

Os séculos XII e XIII seriam sinônimo de um princípio de liberdade para emergentes classes sociais - principalmente, uma classe que posteriormente seria conhecia como de "pesquisadores" - e de uma ampla valorização dos saberes pelos saberes - ou seja, do conhecimento pelo seu conteúdo, não apenas por sua carga ideológica, por seu senso comum, 
por sua condição de estrutura maravilhosa, capaz de refletir no homem segurança e prazer segundo uma iluminação divina. Boni (2000) chega a falar em uma "fome de saber" no período, marcada por uma necessidade de releitura milenar da tradição cristã. A urbanização é tanto acompanhada como incentivada pelo nascimento de centros de ciência, que responderiam por esta "fome". Como persistia a sombra do pecado, ligado ao imaginário teológico, também seria contra as intenções divinas vender o saber, ainda tomado originalmente como um dom de Deus. Neste sentido, o conhecimento deveria ser gratuito. Assim, "enquanto não se monetarizou o ensino, ele permaneceu democrático, constituindo-se, juntamente com a carreira eclesiástica, na grande via de promoção social dos menos favorecidos" (BONI, 2000, p. 15-16).

Devido aos trabalhos de tradução de Boécio, desde o século VI a cristandade possuía acesso à parte da obra de Aristóteles. A partir do século XII, um outro conjunto de obras do filósofo grego é traduzido, somado aos trabalhos de comentaristas, como Avicena, permitindo assim uma leitura profunda do pensamento aristotélico. No século XII, o estudo da Filosofia se reduzirá praticamente ao estudo da lógica pura. A filosofia aristotélica contradizia, no entanto, o modelo de pensamento cristão de cunho profundamente platonista - ou neoplatonista. Esta filosofia aristotélica posicionava Deus como motor, não como criador. O fato cultural de ter Aristóteles sido traduzido fundamentalmente por árabes definiria outro aspecto igualmente relevante: o filósofo viria de mãos pagãs (SARANYANA, 2006, p. 263).

Cabe-nos, no plano dos estudos orientados para a organização dos saberes, compreender o papel de instituições como as bibliotecas e aqueles que direta ou indiretamente determinavam sua formação e desenvolvimento, interferindo em seus documentos. É importante, pois, neste contexto, a rápida propagação dos saberes através de traduções, leituras e compilações, bem como a construção de compêndios, definindo uma práxis da mimese e da produção de um meta-saber característico das ciências documentais. A grande massa de documentos produzida exigia erudição e capacidade de interpretação. É também um período intenso, no âmbito da organização do saberes, de estudos orientados para o reconhecimento de originais de autores, com o avanço das análises filológicas. Em outras palavras, ao buscar a autenticidade das obras estudadas e compiladas, percebe-se um movimento amplo de identificação de autorias.

É relevante observar que o conhecimento no século XIII permite um contexto de ampla exploração teórica. O conhecimento tem um profundo caráter especulativo. Em outras palavras, a Metafísica - ou filosofia primeira - ainda é a base estrutural do pensamento, que sustenta outras disciplinas fundamentais, como Matemática e Física, até ali Filosofia da 
Natureza. Como no ponto de vista aristotélico, a Metafísica era, para muitos autores, a "ciência" fundamental (SARANYANA, 2006). Simultaneamente, a Física seria a base dos estudos iniciais, via que conduziria à Metafísica. Com a presença do pensamento aristotélico, um outro ângulo epistêmico permite conceber o olhar sobre a natureza e sobre os artefatos produzidos pelo homem, dentre eles, o livro.

O "conhecer" e o "complexo" nas práticas de ensino do século XIII se pautariam fundamentalmente na sapiência do mestre e no saber pelo saber - este, por sua vez, se multiplicava nos livros, ou documentos, ou informações registradas a partir de traduções dos mestres da época, que circulavam entre as camadas de alunos cada vez mais amplas. Como destaca Verger (2000, p. 19), uma das marcas do século XIII será o crescimento "na produção de livros à disposição dos estudantes". Ou seja, "graças às novas traduções e às sumas redigidas pelos mestres de Paris e Bolonha, a quantidade de saberes disponível aumentou". Desenvolve-se, paralelamente, uma filosofia orientada para pensar a informação registrada, sua preservação e sua disseminação. Neste período ocorre a passagem da escrita contínua para a escrita com palavras separadas, dando início à leitura silenciosa. Com a escolástica, impõese o texto livro, que influenciaria diretamente o cotidiano do medievo. Os indivíduos iniciavam seu contato com documentos escritos para os mais diversos fins, como testamentos, escrituras de propriedades, compras e vendas, atos públicos, instituições privadas (GHISALBERTI, 2001).

Em diferentes olhares, traduzidos na CI quando da identificação da chamada "sociedade da informação", o período medieval é localizado como ambiente fundamentalmente marcado pela transmissão do conhecimento pela oralidade. Em outras palavras, as narrativas representam a forma de acesso ao conhecimento. O chamado textolivro parece não ganhar relevância nesta contextualização. A ruptura com a Idade Moderna e, em sequência, em um dado mundo pós-moderno, estaria marcada, como nos olhares de Foucault (2002), Benjamin (1985) e Chartier (2001), pela substituição da narrativa pela informação. Objetiva, a informação responderia por uma visão de mundo positiva da realidade - em outros termos, uma visão de mundo "científica" -, enquanto a narrativa, confundida com a transmissão dos contos maravilhosos, lendas e mitos, seria identificada como senso comum. Cabe-nos avaliar criticamente esta divisão ao tratarmos de conceitos como "conhecimento" e "complexidade". Onde estariam as possibilidades de acesso aos saberes: na narrativa ou na informação? De onde partiria a evidência da "complexidade" da realidade física e cultural? Da informação ou da narrativa? Seria possível a separação destas categorias de forma tão clara como propôs a Modernidade? 


\subsection{Das "recentes" "explosões informacionais": o século XX e a filosofia da informação...}

A primeira característica no mundo do século XX seria a "ausência de filosofia", se entendido o filosofar como expressão da Metafísica. Esta, por sua vez, representava a naturalização do elemento "simples", essencial, "anti-complexo" em sua realidade. O objeto do conhecimento é, aqui, necessariamente, "puro". A “explosão informacional” é revelada primeiramente a partir de uma visão fisicalista: "explosão da informacional" representa uma expressão que diz respeito à velocidade e quantidade, não à forma - e muito menos à recepção/apropriação. Em outras palavras, esta outra maneira de creditar o fazer filosófico orienta-se mais na relação entre informação registrada e canais de fluxo de informação, e menos na relação entre estes, seus conteúdos e seus potenciais intérpretes.

Assim, quando falamos de uma filosofia da informação, definida no âmbito epistemológico da CI a partir dos anos 1960, tratamos essencialmente de um olhar pautado na revolução dos meios de comunicação e em sua capacidade de transformar as relações sociais a partir de suas inumeráveis potencialidades. A descrição satírica do cronista Tony (2007, p.118), no semanário ilustrado "Para Todos", sobre os primórdios da presença do telefone dentro da sociedade brasileira evidencia, com clareza, esta relação entre a chamada "explosão informacional" da virada do século XIX para o XX e o nascimento de uma discussão filosófica sobre a informação que reúne técnica e conhecimento em um só argumento. Difundido seu uso - ou seja, popularizado -, o telefone, importante ferramenta de fluxo informacional, já guardaria, em suas manifestações potenciais, os elementos discursivos - e muitos elementos empíricos - que demarcariam a revolução da rede mundial de computadores, produto de origem intrinsecamente ligada aos avanços das telecomunicações.

$\mathrm{Na}$ crônica dos fins dos anos 1920, o autor comenta que o telefone "faz parte integrante da vida de um homem civilizado", imprescindível como qualquer outro objeto ou bem, como o "sal de frutas" e o "jornal". As potencialidades do telefone, segundo o cronista, levariam até uma transformação na sociedade, produzindo um saber distinto, segundo a descrição de Tony. 'Não tardará que appareça uma nova sciencia, a 'telephonomancia', irmã gemea da graphologia , da onirocritica e da hepatoscopia ... Virá ella estabelecer principios e leis referentes ao comportamento humano diante do aparelho telephonico". (TONY, 2007, p. 118, grifo nosso)

O mundo das manifestações inéditas, da inovação, o dito "mundo informacional", é a nova realidade apresentada pela revolução tecnológica do fluxo de discursos. "Quando a 
campainha tilinta, ha os que se atiram para atender. São os nervosos, os afflictos e os avidos de novidades". No conjunto de transformações, também são apresentados os problemas - "ha a phobia telephonica" daqueles que sofrem diante do paradigma da comunicação - ao mesmo tempo que se multiplicam os adeptos às novas soluções, os usuários, levando à "tenephonephilia", marcada pela "caçada de conversas alheias, segredos de Estado, revelações de além-túmulo, palpitações amorosas e palpites de bicho...” . (TONY, 2007, p. 118)

O conhecimento no âmbito dos estudos informacionais é visto como um processo técnico de dinamização de instrumentos de representação e fluxo da informação. Como nos releva Brookes (1980a), a CI se constrói ocupada em um oceano de aplicações práticas do senso comum - aplicações que envolvem cada vez mais os meios de comunicação. Sua fundação, desta forma, descansa sobre o fundo falso de uma construção teórica - a "flutuação do limbo filosófico" no vocabulário brookesiano. Em outras palavras, a crise no regime epistemológico, vinculada à super-produção de registros, assim como se deu no século XIII, levava à reestruturação da visão de mundo no âmbito da organização dos saberes.

Desta maneira, as bases ligadas à "explosão informacional”, à tecnologia da informação, a uma certa sociedade dita "da informação", à emergência da interdisciplinaridade, indicam apenas um praticalismo fundacional, a resposta instantânea por uma demanda, não a construção filosófica profunda e permanentemente refundada - aqui se elabora o cantado conceito de "complexidade". Assim, afirma Brookes (1980a), a CI não apresentou, em seus mitos originais, uma fundamentação teórica - ou seja, não se apresentou como uma "ciência para a informação" de fato.

Brookes (1980a) atentou para uma epistemologia objetiva para uma fundamentação teórica da CI, pois os artefatos do Mundo 3 popperiano, deixavam de ser subjetivos e inacessíveis, ou seja, ao incorporarem em suportes de informação os saberes adquiridos, os cientistas são capazes de transmitir um conhecimento objetificado. No interior de uma epistemologia objetiva para CI é que o autor afirma sua formulação cognitivista da metaciência dos estudos informacionais, que inclui a preocupação com a "posição mental" que o indivíduo ocupa no Mundo 2 - a visão de mundo de cada usuário. Desta forma, na formulação conceitual de CI para Brookes (1980a), é necessário atuar filosoficamente com uma epistemologia de entidades puramente mentais, não com a medição de espectros de informação. Para um conhecimento objetivo, uma epistemologia da informação objetiva.

Percebemos que, em certa medida, a noção de narrativa está contida na relação entre conhecimento e complexidade dentro da CI. No entanto, a necessidade de "objetificação" mensuração - do conhecer diante da expressão do "complexo" conduz os autores a apontar 
uma filosofia da informação focada no ponto de vista que exclui a dança das subjetividades que podem ser encontradas na narrativa, ainda que reconheçam que esta e a informação são expressões de um mesmo contexto epistemológico. Mesmo em sua tentativa de superação do positivismo lógico inicial nos estudos da informação, encontramos ainda a clara necessidade de separação entre o estrato informacional e o estrato narrativo.

\section{Entre o maravilhoso informacional e o maravilhoso narrativo: as vias híbridas da complexidade na organização dos saberes...}

Com efeito, na poesia é de preferir o impossível que persuade, ao possível que não persuade. Aristóteles, Arte Poética

A forma objetiva e aberta como tratamos a "explosão informacional", seja no discurso popular, seja no discurso científico no âmbito da CI, esconde os aspectos ligados à "fetichização" do conceito de informação e, por vezes, a um posicionamento acrítico diante de sua condição original - a condição de conceito. Segundo Morin (2007 a, b), o estudo do conhecimento atual não pode deixar de reconhecer sua complexidade. Esta complexidade diz respeito à noção de que o conhecer não pode ser reduzido à uma forma de visão de mundo por exemplo, a visão teológica, ou a visão filosófica. Logo, o conhecer, em seu sentido complexo, é um caminhar pelo conjunto de elementos que costuram significados em torno dos mecanismos de apreensão da realidade.

Como nos revela Francelin (2003), os estudos que se orientam por um "pensamento complexo" partem do ponto de vista de que há fenômenos que não podem ser explicados com os instrumentos então convencionais. Em outras palavras, temos fenômenos que não são explicáveis com o conjunto de olhares da ciência moderna. Contudo, como visto, nossa "objetificação" da realidade parece definir um regime epistemológico refratário à complexidade. Ao conferir poder a partir da construção de discursos de verdade, para utilizar a expressão de Michel Foucault (2009), ordenamos nossa tradição discursiva em direção a uma categorização que trata o conhecer apenas como manifestação oriunda do informar. Contudo, tanto no estudo do conhecer no século XIII quanto aquele do século XX, percebemos que os "graus de complexidade" são múltiplos - e o impulso para reconhece-los também. Tomando como ponto de observação o ângulo social de análise, notamos que o conceito "informação" pode conduzir à redução da própria noção de complexidade, principalmente se tomamos os usos iniciais deste conceito no campo.

Esta ciência apreendia o fenômeno social da informação como objeto científico - 
tendo o conceito de fenômeno social bastante próximo das teorias de August Comte e Émile Durkheim, de cunho positivista, preocupada com o controle/conquista de uma ordem natural, ou seja, o documento/livro e, por extensão, a informação, como entidades coisificadas. Neste contexto de concorrências e emergências, com uma sociedade burguesa plenamente estabelecida e uma sociedade científica socialmente legitimada, o estudo da narrativa é aparentemente deslocado - a narrativa é retirada da cena social como fonte de transmissão das tradições e retirada da cena científica como fonte de conhecimento.

Diante da práxis do conhecer "científico" no século XIII, percebemos, no entanto, como a informação registrada era causa e produto do conhecimento, assim como a CI atualmente aponta, em seu olhar sobre o "documento", como lembram os trabalhos de Hjorland (2000) e Frohmann (1999). Assim, se entendemos que no passado a narrativa se expressava como forma de conhecer - e base da "complexidade do mundo" - e a informação, no mundo contemporâneo, é tratada como nossa "única" forma de conhecer, objetiva por natureza - nossa expressão "material" da complexidade -, reduzimos a realidade histórica a dois períodos entre mil anos que, na verdade, não apresentam, em seu cotidiano, uma cisão que impeça a interpretação comparativa. Tratando a narrativa como conjunto de vozes que registra e transmite os saberes acumulados pelas culturas em sua diversidade, e a informação como elemento quantificável, que, do mesmo modo, registra e transmite, de maneira objetiva, os saberes acumulados, percebemos que tanto aquela como esta são fruto e semente, no Medievo e na contemporaneidade, de um "modo de conhecer" estruturado em uma dada "complexidade"; são semente e fruto, na ontem e hoje, das operações e mutações do próprio processo de conhecer. Mais do que isso, a informação se apresenta sob os tecidos da matéria narrada; a narrativa, por sua vez, "surge", em diferentes expressões, como o registro da informação.

No entanto, ao conferir à informação sua condição de "fenômeno em si", adotando-a como "o" objeto, como em Borko (1968), ou ainda, como uma objetividade possível, como em Brookes (1980 a, b, c), a discursividade do campo da organização dos saberes termina por identificá-la (assim como a sociedade extra-muros universitários) como o "maravilhoso" do século XX. Informação e narrativa restariam como manifestações identitárias de aproximação ao conhecimento em períodos distintos. Na Idade Média, o conhecimento se dava pela narrativa, no mundo atual, pela informação. Percebemos, porém, que o conhecimento e o maravilhoso, terminam se entrecruzando, sem uma clara distinção ali e aqui. E tal divisão não passaria de uma linha panorâmica distante das possibilidades hermenêuticas de compreensão dos fenômenos que envolvem a produção e a circulação dos saberes. 


\subsection{Nós cremos, nós vemos: o maravilhoso no Medievo...}

Em determinados discursos historiográficos, como aquele oriundo de Foucault (2002) e Chartier (2001), identificamos a "narrativa" como modalidade de expressão e transmissão de saberes "deposta" pela informação. A partir da revolução dos suportes da informação, fundamentalmente a partir da "explosão informacional" gutenbergiana, passamos a tratar o acesso ao conhecimento como um processo de aquisição de informações. A informação, entidade objetiva, seria a unidade de representação e transmissão das culturas, atuando tanto como regulador de sistemas como fator de transformação social (MARTELETO, 1987). De outro modo, a narrativa, povoada de ruídos, para usar o vocabulário de Shannon \& Weaver, ou entraves para transmissão das mensagens, seria tomada como matéria ausente do discurso sobre a aquisição do conhecimento na CI.

Imersa no imaginário da Idade Média, esta "narrativa" seria o modo fundamental de "conhecer" que perpassa os séculos até a Idade Moderna - "modo de conhecer" fundamentalmente "poluído", onde as mensagens viriam envolvidas em uma teia de visões de mundo ligadas à teologia, à filosofia e às múltiplas práticas oriundas de um acusado "senso comum". Este "artesanato" de significados se confundia com os elementos que fariam o empirismo afastar, na Modernidade, a relação entre objeto e observador, relação estendida pelo positivismo dentro das ciências sociais.

A ausência de uma estrutura empírica no olhar científico dos séculos anteriores e a criticada intimidade entre objeto e observador levariam - ou tendiam a levar - até uma "dessocialização" dos objetos de pesquisa, afastando sua carga significativa e simbólica, fundamentalmente seu caráter maravilhoso, que o identificaria com os regimes epistemológicos da tradição medieval. Com o positivismo esta postura seria "contornada": as relações sociais seriam coisificadas à moda dos objetos do mundo 1 de Popper, o das entidades físicas, e o observador se portaria apenas como um ente isolado do contexto de fundação e manifestação do objeto. Ficavam assim negligenciadas todas as vozes que compunham os jogos narrativos que se multiplicavam no século XIX e XX, ligadas, por exemplo, à discursividade do mercado e de minorias culturais que ao longo do século anterior viriam reivindicar suas identidades, manifestações estas propagadas pelas maravilhas informacionais do século XX. O "maravilhoso", no entanto, é comumente apenas refletido no contexto do medievo, como agora observaremos.

Jacques Le Goff (1983), em seu estudo "O maravilhoso no ocidente medieval", 
investiga a relação entre a noção de "maravilhoso" e os indivíduos no ocidente ao longo do medievo. Em seu trabalho, o historiador aproxima a ideia de "maravilhoso" aos termos que correspondem ao mesmo significado. Assim, "maravilhoso", segundo o conceito que aparecerá entre os séculos XII e XIII, significa, em linhas gerais, o plural do termo mirabilis, ou seja, mirabilia. Le Goff chama a atenção para o fato de que, onde percebemos, na linguagem contemporânea, uma categoria terminológica - o "maravilhoso" -, para os indivíduos do Medievo este representava um conjunto de objetos. Para além de coisas "que o homem pode admirar com os olhos" (LE GOFF, 1983, p. 20), o "maravilhoso" representa a coleção de manifestações que provocam o olhar do observador.

No Ocidente medieval, o historiador observa três elementos gerais que cercam a questão. O primeiro, que trata da atitude dos homens da Idade Média, aponta para o fato da "herança do maravilhoso". Em certa medida, o "maravilhoso" no Medievo não representa um desenvolvimento obrigatório, mas é fruto do recolhimento e da recepção de "estratos antigos", ou seja, do "maravilhoso anterior". Neste aspecto, elementos maravilhosos dispersos nas crenças, nos textos e na hagiografia são recuperados a partir do século XII. O segundo elemento discutido por Le Goff (1983) indica a relação de tolerância entre a Igreja e os limites do maravilhoso. O discurso teológico permitirá, de certo modo, o avanço do "maravilhoso" no início do Duzentos - assim como vimos que a Igreja virá tolerar, em certa medida, o avanço de escolas "laicizadas" diante das movimentações no regime epistemológico do medievo. Ali, segundo a reflexão do historiador, o "maravilhoso" já não era tão perigoso, imerso que estava na cultura laica. Por fim, temos, como terceiro elemento de discussão, o processo de "estetização" do "maravilhoso", ou a construção de sua expressão imagética que permitiria adoração e culto (LE GOFF, 1983, p. 21).

Enquanto a igreja promovia, durante a alta Idade Média, entre os séculos V e XI, um controle sobre o "maravilhoso", a partir da necessidade de ocultar elementos perigosos, este cerceamento cultural será diluído no correr do século XII, permitindo uma "irrupção do maravilhoso na cultura dos doutos" (LE GOFF, 1983, p. 22). O romance de cavalaria, manifestação peculiar e identitária do período, fundar-se-á no discurso que se tece a partir de uma série de maravilhas. O "maravilhoso" tem como características fundamentais a) o fato de ser produzido por forças sobrenaturais b) sua imprevisibilidade e c) sua aparição. Um conjunto de forças, por trás da coleção de objetos que se apresenta ao miraculoso, age de maneira a dar forma à expressão maravilhosa. No mundo cristão, o maravilhoso é expressado no milagre. Seria, o acontecimento milagroso, o "maravilhoso permitido", ou "naturalnaturalizado", ainda que oriundo de "poderes sobrenaturais". Apenas um seria o Autor desta 
manifestação do "maravilhoso": Deus (LE GOFF, 1983, p. 25).

O milagre como "maravilhoso regimentado" é o que o historiador abordará como "racionalização das maravilhas". Esta regulamentação esvazia o "maravilhoso", ao racionalizar e afastá-lo de suas matérias fundamentais. O "maravilhoso" deixa, assim, de ser (interpretado como) algo sobrenatural, ainda que de forças ocultas advenha; deixa, assim, de ser imprevisível, ainda que a previsibilidade de seu acontecimento não possa ser delineada. Estas possíveis subversões se dão, de fato, pois o Autor do "maravilhoso", ainda que oculto, é discursivamente determinado a partir de sua condição de "ato puro" no contexto discursivo (ou no jogo de interpretações comungadas). Se há Deus, existe regularidade, e o milagre, expressão do "maravilhoso", ainda que misterioso e imprevisível, é paradoxalmente natural, e está determinado na regularidade divina. Assim, sua aparição é algo que está "previsto" e o milagre se realiza através de intermediários, ou seja, através dos santos (LE GOFF, 1983, p. 25).

A função do "maravilhoso" no cotidiano medieval expressa, assim, o "contrapeso à banalidade e à regularidade do quotidiano", apresenta-se como "forma de resistência à ideologia oficial". Seres fabulosos se multiplicam e principia-se uma desumanização do universo, em direção a um mundo animalista. Recusa-se, assim, o humanismo, matéria do cristianismo medieval, ligado à ideia do homem feito à imagem de Deus. O indivíduo aqui é determinado pela sua aproximação à natureza (LE GOFF, 1985, p. 27).

\subsection{Foi quando nos pegamos a admirar: o maravilhoso "moderno-pós-moderno"...}

Como mencionado, ligada às recentes "explosões informacionais" dos séculos XIX e $\mathrm{XX}$, a CI percebe o conhecimento como um processo de apropriação de informações. De forma essencial, a informação que circula através dos canais das novas tecnologias da linguagem será definida como o objeto complexo do conhecer. As potencialidades abertas pela Internet dariam significado e sedimentariam esta manifestação. No entanto, através da mencionada crônica da década de 1920, que trata de um dos canais de fluxo informacional que revolucionará o Oitocentos e o Novecentos, encontramos as instâncias centrais do discurso da epistemologia informacional.

Diante do telefone, releva Tony (2007, p. 118, grifo nosso), "como todas as divindades", "ninguém pode obter delle o que deseja, sem obedecer a certos ritos". Desta maneira, "os fiéis do telephone nem sempre se conformam com esse ritual commovente ou o praticam mal e dahi as constantes blasphemias de que é victima, e as heresias innumeras que 
surgem dentro do dogma telephonico". Aqueles que decidem por não usar o telefone, os "atheus do telephone", são os que "não acreditam nele e preferem o serviço de recados, o galopim tatibitati ou o moleque brasileiro, cheio de esquecimentos e de assobios, aos tintinabulantes benefícios da invenção de Graham Bell”.

Como registra Marteleto (1997, p. 177), em uma dita pós-modernidade, “a própria natureza do conhecimento é então alterada, pois este não poderá passar pelos novos canais de comunicação, e portanto tornar-se operacional, se não for traduzido em bits de informação", além de precisar ser transformado em mercadoria informacional, pela apropriação do mercado, que lhe confere os graus de verdade. Nesta pós-modernidade, abordada temporalmente como fruto das transformações no regime epistemológico de meados do século XX, não há uma revolução sumária, que anula todas as manifestações da História e inventa um novo modo de relação social. Ao contrário, através de um acúmulo de apropriações, as relações chamadas pós-modernas reinterpretam os gestos e movimentos anteriores, colocados, estes, sob e sobre diferentes ondas de uso e dispersão.

As crenças, anteriormente pautadas nas Escrituras Sagradas, continuam pautando-se em escrituras - textos -, hoje dispersas em diferentes meios voláteis de inscrição, como a televisão e os portais on line. A hagiografia é apenas substituída pelo estudo e propogação da vida dos ídolos midiáticos e pelos epítetos acadêmicos. O mundo hipermoderno imaginado na alegoria de Aldous Huxley (1983), voltado para germinações e proliferações mediadas por tecnologias, se concretiza no progresso via informação. O maravilhoso está dado na seguinte profecia moderna: haverá uma sociedade boa e justa, pois ela terá necessidade de informação, fará uso das tecnologias da informação e viverá para produzir mais informação.

A morte de Deus anunciada por Nietzsche no Oitocentos define o século seguinte como suposto "século pagão". Temos, desta maneira, a expressão de um cotidiano secular ao longo do Novecentos, marcado por um retorno ao indivíduo afastado do discurso teológico, mas devoto do verbo tecnológico. O "paganismo informacional" sugere o retorno ao "maravilhoso", porém as maravilhas são representadas pelos conjuntos de forças diferentes, ou seja, objetos e serviços "inseridos" nestes objetos - os pacotes tecnológicos - de ordem tecnocomunicacional. O "maravilhoso", para além de uma categoria, também representa, no contexto contemporâneo, como no Medievo, um conjunto de objetos, uma coleção de produtos e processos informatizados disponíveis tanto para imaginar, quanto para ver, quanto para vivenciar - cuja materialidade vai muito além sua estrutura física, multiplicada e tensionada que é por sua “infraestrutura simbólica intangível”.

A informação se torna bem comum de diferentes domínios do conhecimento. No 
âmbito dos saberes chamados científicos, também ela ganhará status de objeto. Assim, a informação, enquanto maravilhoso do século XX, também se torna elemento do discurso dos "doutos". Cientistas e pesquisadores passam a estudar a informação em todas as suas "aparições", ou "epifanias" - vide o conceito de Borko (1968). Um certo "movimento interdisciplinar", resposta política para uma "pedagogia da complexidade", eclode na segunda metade do Novecentos, incentivando a criação de um discurso científico da informação, que, por sua vez, traz no seu encalço a emergência de uma filosofia distinta para a informação. Regimentar o milagre do aparecimento da informação é o labor deste personagem histórico. Sua prática retira da informação seus significados, a esvazia, tornando-a objeto, "coisa". O romance e as narrativas fílmicas tratadas como o gênero da ficção científica serão as manifestações representativas desta condição, apresentando a série de maravilhas ofertadas pelas mutações tecnológicas.

Como Deus, a informação é, por vezes, tomada como motor imóvel que faz o mundo se mover. Ela está em todo lugar. Cabe ao pesquisador informacional defini-la, para dominála, ainda que não queira retirar dela sua "essência maravilhosa" - sua condição de valor que substitui o trabalho como matéria de precificação. A informação está presente na série de maravilhas que se iluminam a cada dia... a nova ferramenta de email, o novo aparelho celular, a nova câmera digital, a nova "rede social", seres fabulosos que levam o homem à sua comparação do humano com a máquina - ou o abandono do humanismo moderno pelo maquinismo.

\section{Considerações finais}

Ora, o maravilhoso agrada, e a prova está em que todos quantos narram alguma coisa acrescentam pormenores imaginários, com intuito de agradar.

Aristóteles, Arte Poética

Assim como podemos perceber que o século XIII é um período de relação direta com o conhecimento registrado e pautado em uma estrutura objetiva, sendo o "complexo" o próprio registro da informação em si, aquém da condição do "maravilhoso" disperso nas narrativas, assim também percebemos que, no século XX, a informação é fruto de narrativas múltiplas e é cultuada, para além de sua suposta objetividade, com o resultado de uma série de "maravilhas". Logo, se enxergamos o maravilhoso e o informacional no Medievo, também no mundo contemporâneo podemos perceber esta convivência.

A informação representaria o reflexo da complexidade no mundo contemporâneo. Em 
certa medida, assim como a narrativa do conto maravilhoso, a informação designaria a via contrária ao banal e ao regular no cotidiano. No entanto, neste âmbito, o homem é pautado em sua relação com a máquina. A “desumanização” se dá a partir das transformações miraculosas da e para as tecnologias da informação. A série de produtos e serviços informações, observada em sua teia simbólica, que envolve mercado, sociedade, cultura, etc., nada mais é que o conjunto de narrativas que recolocam o "maravilhoso" em nosso cotidiano. A própria “explosão informacional” conduz nosso imaginário à relação do duplo maravilha-informação.

Afora as características estruturais do maravilhoso no medievo, é também necessário, nos convoca Le Goff (1983, p. 27), um olhar social sobre o fato, ou seja, a construção diária do imaginário sobre o "maravilhoso". Desta maneira, "o amplo alcance do maravilhoso medieval depende exactamente de um seu desenvolvimento interno, pelo qual o maravilhoso se estimula, se alarga e assume proporções ambiciosas e por vezes extravagantes”. Por vezes, o maravilhoso é visto apenas a partir de sua condição primeira, sua sobrenaturalidade. No entanto, ele se revelará exatamente no seio de uma realidade social. Assim também se dá com a informação. Por vezes as nuances de apresentação da informação levantam um caráter miraculoso, o impossível. A ficção científica talvez represente esta realidade. Por mais “improvável”, parece atualizar-se à medida que as novidades tecnológicas arrancam suspiros de admiração dos incrédulos em suas epifanias. As maravilhas de expressões de serviços e produtos tecnocomunicacionais são fenômenos desta condição.

Ao conceber, de forma rasa, a Idade Média como campo marcado pelo domínio religioso percebemos como negligenciamos o processo de "formação do conhecimento" e reduzimos nosso reconhecimento da "complexidade" deste período. O maravilhoso, como marca identitária da narrativa, de fato, não pode ser tomado como única expressão do conhecimento no medievo. Por sua vez, tendemos a definir, principalmente a partir do positivismo na epistemologia da CI, a informação como fonte de domínio do mercado, tendendo a rejeitar as outras formas de produção de saberes, e fundar a complexidade nas transformações tecnológicas. O conhecimento objetivo, como expressão da informação, seria a única expressão do regime epistemológico no contexto da pós-modernidade. Sabemos, no entanto, que ambos os períodos escondem e relevam contingências que redistribuem estas expressões, demonstrando a forma como ambas, lá e aqui, não apenas coexistem, como convivem em uma harmonia simbólica, ainda que, por vezes, recortada.

Diferentes são as formas de "recuperação do maravilhoso". A recuperação cristã "canalizou o maravilhoso", focando-o no milagre e em sua simbologia (LE GOFF, 1983, p. 30). A recuperação científica passou a buscar as possibilidades de ligar os mirabilia e o 
mundo natural. A informação seria expressa, do mesmo modo que a narrativa, como manifestação do "maravilhoso cotidiano". Este reconhecimento se dá apreendendo o maravilhoso como natural. O maravilhoso narrativo é, permanentemente, a tentativa de ultrapassar o real, não no sentido de atingir o irreal, mas de suprimir a ordem do real. O maravilhoso informacional é, por sua vez, a expressão da intermitente necessidade de multiplicar e renovar o real, não no sentido de retirar-lhe sua "realidade" presente, mas de suprimir a possibilidade de seu estancamento.

\section{Referências}

BENJAMIN, W. Narrador; considerações sobre a obra de Nikolai Leskov. In: Magia e técnica, arte e política: ensaios sobre literatura e história da cultra. Obras escolhidas. v. 1. São Paulo: Brasiliense, 1985.

BONI, L.A. Prefácio. In: ULLMANN, Reinholdo A . A universidade medieval. 2. ed. Porto Alegre: EDIPUCRS, 2000. (Coleção Filosofia, v.III)

BORKO, H. Information science: what is it? American Documentation, jan, 1968.

BOYCE, B.R.; KRAFT, D.H. Principles and theories in information science. Annual review of information science and technology (ARIST), v. 20, 1985.

BROOKES, B.C. The foundations of information science. Part I. Philosophical aspects. Journal of Information Science, v. 2, p. 125-133, 1980a.

The foundations of information science. Parte II. Quantitative aspects: classes of things and the challenge of human individuality. Journal of Information Science, v. 2, p. 209-221, 1980b.

The foundations of information science. Parte III. Quantitative aspects: objective maps and subjective landscapes. Journal of Information Science, v. 2, p. 269-275, 1980c.

The foundations of information science. Part IV. Information science: the changing paradigm. Journal of Infomation Science, v. 3, p. 3-12, 1981.

BURKE, P. Os problemas causados por Gutemberg: a explosão da informação nos primórdios da Europa moderna. Estudos Avançados, São Paulo, v. 16, n. 44, p. 173-185, 2002.

CHARTIER, R. Uma crise da história? A história entre a narração e o conhecimento. In: PESAVENTO, S. J. Fronteiras do milênio. Porto Alegre: Universidade UFRGS, 2001. p. 115-140.

DAY, R. Poststructuralism and information studies. Annual review of information scicence social and technology (ARIST), v. 39, p. 575-609, 2005.

FOUCAULT, Michel. As palavras e as coisas: uma arqueologia das ciências humanas. 
Tradução Salma Tannus Muchail. 8. ed. Martins Fontes: São Paulo, 2002. (Coleção Trópicos).

A ordem do discurso. São Paulo: Loyola, 2009.

FRANCELIN, M.M. A epistemologia da complexidade e a ciência da informação. Ci. Inf., Brasília, v. 32, n. 2, p. 64-68, maio/ago. 2003.

FROHMANN, B. The power of images: a discourse of images: a discourse analysis of cognitive viewpoint. Journal of Documentation, v. 48, n. 4, p. 365-386, 1992. 303, 2009.

Revisiting “what is a document? Journal of Documentation, v. 65, n. 2, p. 291-

GHISALBERTI, A . As raízes medievais do pensamento moderno. Porto Alegre: EDIPUCRS, 2001.

HJORLAND, B. Documents, memory instituitions and information science. Journal of Documentation, v. 56, n. 1, p. 27-41, jan. 2000.

HUXLEY, A. Admirável mundo novo. São Paulo: Círculo do Livro, 1983.

KROLL, W. Historia de la filologia clássica. Barcelona: Labor, 1941.

LE GOFF, J. O maravilhoso e o quotidiano no ocidente medieval. Lisboa: Edições 70, 1983.

MARTELETO, R.M. Informação: elemento regulador dos sistemas, fator de mudança social ou fenômeno pós-moderno?. Ciência da Informação, Brasília, v. 16, n. 2, p. 169-180, jul./dez. 1987.

MORIN, E. Ciência com consciência. 10 ed. Rio de Janeiro: Bertrand Brasil, 2007a.

Os desafios da complexidade. In: JORNADAS TEMÁTICAS (1998: Paris, França: 1998). A religião dos saberes: o desafio do século XXI. Rio de Janeiro: Bertrand Brasil, 2007b. p. 559-567.

ORTEGA Y GASSET, J. Missão do bibliotecário. Brasília: Briquet de Lemos, 2006.

PINHEIRO, L.V.R. Gênese da Ciência da Informação ou sinais anunciadores da nova área. In: AQUINO, Mirian de Albuquerque (org.). O campo da ciência da informação: gênese, conexões e especificidades. João Pessoa: Ed. Universitária, 2002. p. 61-86.

SHERA, J.H.; CLEVELAND, D.B. History and foundations of information science. Annual review of information science and technology (ARIST), v. 12, p.249-275, 1977.

SOBRAL, J. O desenhista invisível. Rio de Janeiro: Folha Seca, 2007.

SILVA, A.M. da; RIBEIRO, F. Das ciências documentais à ciência da informação: ensaio epistemológico para um novo modelo curricular. Porto: edições Afrontamento, 2002. 
(Colecção Biblioteca das Ciências do Homem, Plural, 4)

SOUSA, E. Comentários. In: ARISTÓTELES. Poética. Porto Alegre: Editora Globo, 1966.

ULLMANN, R.A. A universidade medieval. 2. ed. Porto Alegre: EDIPUCRS, 2000. (Coleção Filosofia, v.III)

VERGER, J. Cultura, ensino e sociedade no ocidente nos séculos XII e XIII. Bauru: EDUSC, 2001. (Coleção histórica)

WERSIG, G.; NEVELLING, U. The phenomena of interest to Information Science. The information scientist, v. 9, n. 4, p. 127-140, dec. 1975. 